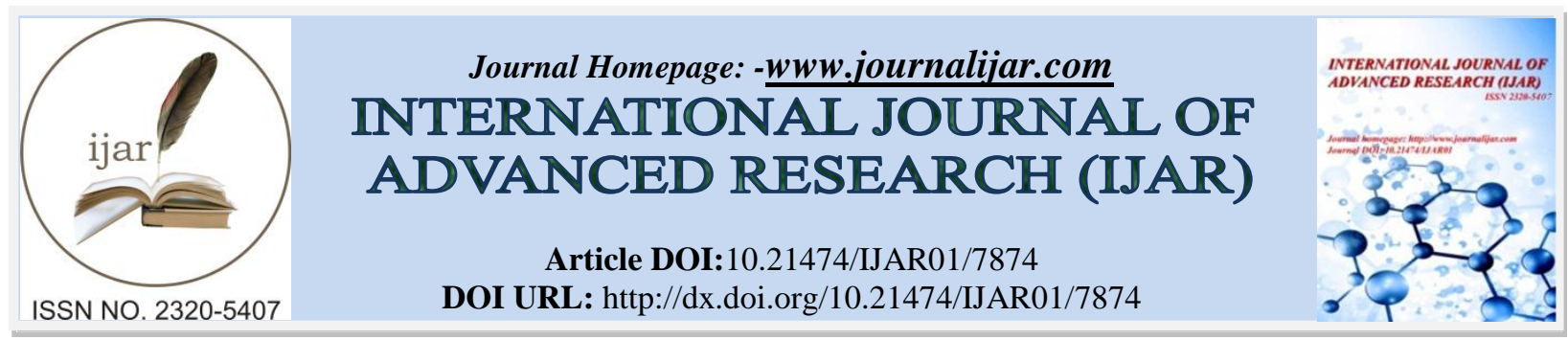

RESEARCH ARTICLE

\title{
RISK FACTORS OF EARLY AND LATE ONSET PREECLAMPSIA IN SAMPLE OF IRAQI WOMEN.
}

Dr. Dalyathamer Ahmed.

Cabog , Ficog obstetrics and gynecology department college of medicine / al-iraqiauniversity.

\section{Manuscript Info}

Manuscript History

Received: 10 August 2018

Final Accepted: 12 September 2018

Published: October 2018

\begin{abstract}
Objective: The aim of this study was to identify the differences in risk factors between early and late onset pre-eclampsia in sample of Iraqi women.

Material and methods: This retrospective study was carried out involving pregnancies with pre-eclampsia (65 early onset and 143 late onset) and 235 controls at different hospitals in Baghdad city between 1 January 2014 and 31 December 2017. The data were reviewed from antenatal and delivery records.

Results: Factors which were significantly associated with increased risk for early onset pre-eclampsia were history of chronic hypertension and higher BMI before pregnancy while family history of chronic hypertension and increased maternal age was significantly associated with increased risk for only late onset pre-eclampsia.

Previous history of preeclampsia, Nulliparity and family history of diabetes are associated with both early and late preeclampsia.

Conclusions: Early- and late-onset preeclampsia may have the same etiological features but they differ with regard to several risk factors, and can lead to different outcomes, so they should be treated as distinct entities from an etiological and prognostic standpoint.

Identification of the risk factors for each type is of value to obstetricians in recognizing patients at risk for pre-eclampsia and in implementing primary prevention.
\end{abstract}

Copy Right, IJAR, 2018,. All rights reserved.

\section{Introduction:-}

Preeclampsia is a pregnancy-related hypertensive disorder occurring usually after 20 weeks of gestation. If left untreated, it progresses to eclampsia. ${ }^{(1)}$

Preeclampsia syndrome is a symptoms that consists of hypertension and proteinuria during gestation. ${ }^{(2)}$

All over the world, Pre-eclampsia complicates about $3 \%$ of pregnancies, and all hypertensive disorders affect about five to $10 \%$ of pregnancies. ${ }^{(2,3)}$

A few studies were done in the developing world, to estimate the incidence of preeclampsia and eclampsia. Some found that it is ranging from a low of $4 \%$ of all deliveries to as high as $18 \%$ in parts of Africa. ${ }^{(4)}$ A close result was founded by other study $1.8 \%$ to $16.7 \% .^{(1)}$

In the United States, incidence rates for Preeclampsia and related hypertensive disorders of pregnancy range from 5$8 \%$ of all births. ${ }^{(4,5)}$ preeclampsia alone - in the United States, Canada and Western Europe, impact 2-5\%. ${ }^{(4,5)}$ 
It was found that a woman in developing countries is seven times as likely to develop preeclampsia than a woman in a developed country. From $10-25 \%$ of these cases will result in maternal death. ${ }^{(6)}$

early and late preeclampsia (PE) are thought to be different disease entities, They appear to develop from different hemodynamic states. ${ }^{(7)}$ and the two pre-eclampsia types should be treated as distinct entities from an etiologic and prognostic standpoint. ${ }^{(8)}$

There is evidence that more severe disease is associated with early onset, prior to 34 weeks' gestation, supporting the concept that the etiology of this disease may be different from that of later onset pre-eclampsia. ${ }^{(9)}$

Early onset disease appears to be mediated by the placenta, and is associated with abnormal uterine artery Doppler flow, fetal growth restriction, and adverse maternal and fetal outcomes. ${ }^{(10,11)}$ Later onset of the disease (after 34 weeks' gestation) has been linked to maternal "constitutional" factors, such as body mass index (BMI), and may be associated with more favorable outcomes. ${ }^{(11)}$ Because the etiology of the disease appears to vary according to the time of presentation, so too do the maternal hemodynamics. ${ }^{(12)}$

\section{Material and method:-}

A retrospective analysis including total number of all reported cases of preeclampsia in different Baghdad hospitals between 1 January 2015 and 31 December 2017.

The data were reviewed from antenatal and delivery records including all pregnant with gestational age of 20 weeks or more and estimate fetal weight of $\geq 500 \mathrm{~g}$ delivered, including demographic data, information abstracted on age, parity, previous miscarriage, previous preterm labor,pre-pregnancy weight, height, blood pressure.

Perinatal history for every women in the study was recorded, including Gestational age at delivery, preterm delivery, birth weight (g), birth weight $<2500$ gram, Cesarean delivery, Apgar scores at $1 \mathrm{~min}$ and at $5 \mathrm{~min}$.

Study population and exposure variable Control population was including all women who had no evidence of preeclampsia or any hypertensive disorder during pregnancy and who delivered an infant at term $(\geq 37$ weeks of gestation), $(\mathrm{n}=235)$.

All women who had a confirmed diagnosis of preeclampsia were included, (total $n=208$ ), after excluding those women who diagnosed to have pre-gestational hypertension, gestational hypertention or diabetes mellitus.

The research protocol was reviewed and approved by theScientific Committee in the college of Medicine/Al-Iraqia University and theMinistry of Higher Education and Scientific Research.

\section{Outcomes}

The clinical definition of preeclampsia during the study period was a rise in blood pressure $(\geq 140 / 90 \mathrm{~mm} \mathrm{Hg})$ on at least 2 occasions ( $>6$ hours apart) combined with proteinuria ( $\geq 0.3 \mathrm{~g} / 24$ hours or +1 or more ondipstick) ( $>30 \mathrm{mg} / \mathrm{dL}$ on two or more random specimens collected $>$ four hours apart) according to American College of Obstetricians and Gynecologists (ACOG) guidelines. ${ }^{(13)}$

Recently it has been suggested that early ( $<34$ completed weeks gestation) and late ( $>34$ completed weeks gestation) onset preeclampsia may have different etiologies.

So preeclampsia cases were categorized according to gestational age at onset using the cut-point suggested by von Dadelszen et al. ${ }^{(14)}$ early preeclampsia $(n=65)$, late preeclampsia $(n=143)$

\section{Covariates}

The covariates that are considered in this research included maternal socio-demographic and behavioral characteristics including maternal age, educational attainment, employment status, cigarette smoking during pregnancy. Also considered were maternal reproductive and medical histories including parity, prior history of hypertensive disorders during pregnancy, history of abortion, maternal height, weight and infant gender. Parity was reported as the number of previous pregnancies lasting more than 24 weeks gestation. Pre-pregnancy body mass index (BMI) was calculated as weight (in kilograms) divided by the square of height (in meters), (underweight: (BMI $<20 \mathrm{~kg} / \mathrm{m} 2$ ); normal: (BMI 20-24.9 kg/m2); overweight: (BMI25.0-29.9 kg/m2); obese: (BMI $30 \mathrm{~kg} / \mathrm{m} 2$ ). 


\section{Statistical analysis}

Multivariable logistic regression procedures were employed to calculate odd ratios (OR) of potential risk factors associated with preeclampsia. Confidence intervals, at the $95 \%$ level were also reported for each unadjusted and adjusted OR. Confounding was assessed by entering potential cofounders into a logistic regression model one at a time, and by comparing the adjusted and unadjusted ORs.

\section{Statistical methods}

Odds ratios with $95 \%$ confidence intervals were calculated by unconditional logistic regression analysis with adjustments for maternal and infant characteristics.

Mean \pm standard deviation and percentage were calculated. The risk factors that were significant on the univariate analysis were entered into a multivariate regression analysis. Adjusted odds ratio (OR) with $95 \%$ confidence interval (CI) was calculated. A P-value $<0.05$ was considered statistically significant.

All analyses were completed using SPSS, version 16.0 statistical software.

\section{Result:-}

The total number of cases in this study is (443) divided into control group (235), early preeclampsia (65) and late preeclampsia (143).

Table 1:- Demographic characteristics of study population

\begin{tabular}{|l|l|l|l|l|l|}
\hline Characteristic & Control $\mathrm{n}=235$ & $\begin{array}{l}\text { Early onset } \\
\mathrm{n}=65\end{array}$ & $\mathrm{P}$-value & $\begin{array}{l}\text { Late onset } \\
\mathrm{n}=143\end{array}$ & $\mathrm{P}$-value \\
\hline Age mean (years) & 29 & 28 & $\mathrm{P}=0.0755$ & 33 & $\mathrm{P}<0.0001$ \\
\hline Nulliparity & $139(59.1 \%)$ & $17(27 \%)$ & $\mathrm{P}<0.0001$ & $67(47 \%)$ & $\mathrm{P}=0.0221$ \\
\hline $\begin{array}{l}\text { Previous } \\
\text { miscarriage }\end{array}$ & $51(21.7 \%)$ & $11(17 \%)$ & $\mathrm{P}=0.4084$ & $35(24.5 \%)$ & $\mathrm{P}=0.5295$ \\
\hline $\begin{array}{l}\text { Previous preterm } \\
\text { delivery }\end{array}$ & $44(18.7 \%)$ & $15(23 \%)$ & $\mathrm{P}=0.4406$ & $26(18.18 \%)$ & $\mathrm{P}=0.8997$ \\
\hline
\end{tabular}

Table -1- shows the Demographic characteristic of the studied group, we see that the mean maternal age were significantly higher in late preeclampsia group $(\mathrm{P}<0.0001)$, Nulliparity was found as highly significant risk factor for early onset preeclampsia $(\mathrm{P}<0.0001)$ and significant risk factor for late onset preeclampsia $(\mathrm{P}=0.0221)$, Previous miscarriage and Previous preterm delivery were found not to have an effect on the incidence and onset of preeclampsia.

Table 2:-Results of multivariate logistic regression analysis

\begin{tabular}{|c|c|c|c|c|}
\hline \multirow[t]{2}{*}{ Risk factor } & \multicolumn{2}{|l|}{ Early onset } & \multicolumn{2}{|l|}{ Late onset } \\
\hline & $\begin{array}{l}\text { Adjusted } \\
(95 \% \text { CI })^{*}\end{array}$ & P-value & $\begin{array}{ll}\text { Adjusted } & \text { OR } \\
(95 \% \text { CI }) & \end{array}$ & P-value \\
\hline Previous history of preeclampsia & $\begin{array}{lll}3.38 & (1.87 & - \\
6.11) & & \end{array}$ & $\mathrm{P}=0.0001$ & $\begin{array}{lll}4.92 & (3.09 & - \\
7.85) & & \end{array}$ & $\mathrm{P}<0.0001$ \\
\hline History of chronic hypertension & $3.8497(2.1-6.9)$ & $\mathrm{P}<0.0001$ & $\begin{array}{ll}0.856 \quad(0.49- \\
1.47)\end{array}$ & $\mathrm{P}=0.5639$ \\
\hline Family history of hypertension & $0.78(0.43-1.42)$ & $\mathrm{P}=0.4197$ & $\begin{array}{ll}6.65 & (4.10- \\
10.77 & \end{array}$ & $\mathrm{P}<0.0001$ \\
\hline Family history of diabetes & $\begin{array}{lll}2.79 & (1.53 \quad- & \\
5.08) & & \end{array}$ & $\mathrm{P}=0.0008$ & $3.7(2.33-5.93)$ & $\mathrm{P}<0.0001$ \\
\hline $\begin{array}{l}\text { Pre-pregnancy body mass index }<20 \\
\mathrm{~kg} / \mathrm{m}^{2}\end{array}$ & $\begin{array}{ll}0.04 & (0.01 \\
0.15) & \\
\end{array}$ & $\mathrm{P}=0.0732$ & $\begin{array}{lll}0.39 & (0.26 & - \\
0.61) & & \\
\end{array}$ & $\mathrm{P}=0.6421$ \\
\hline $\begin{array}{l}\text { Pre-pregnancy body mass index } 25- \\
29.9 \mathrm{~kg} / \mathrm{m}^{2}\end{array}$ & $\begin{array}{lll}0.53 & (0.26 & - \\
1.08) & & \end{array}$ & $\mathrm{P}=0.0815$ & $\begin{array}{lll}1.52 & (0.88 & - \\
2.60) & & \end{array}$ & $\mathrm{P}=0.1300$ \\
\hline
\end{tabular}




\begin{tabular}{|c|c|c|c|c|}
\hline $\begin{array}{l}\text { Pre-pregnancy body mass index } 30 \\
\mathrm{~kg} / \mathrm{m}^{2}\end{array}$ & $\begin{array}{lll}10.04 & (5.39 \quad- \\
18.72)\end{array}$ & $\mathrm{P}<0.0001$ & $\begin{array}{lll}1.19 & (0.70 \quad- \\
1.99) & \end{array}$ & $\mathrm{P}=0.5222$ \\
\hline
\end{tabular}

Table -2-Previous history of preeclampsia and Family history of diabetes are highly significant risk factor for both early and late preeclampsia $(\mathrm{P}=0.0001$ and $\mathrm{P}<0.0001)(\mathrm{P}=0.0008$ and $\mathrm{P}<0.0001)$ respectively, while history of chronic hypertension and Pre-pregnancy body mass index $30 \mathrm{~kg} / \mathrm{m}^{2}$ are highly significant risk factor for early preeclampsia alone $(\mathrm{P}$ value for both $<0.0001)$, Family history of hypertension is highly significant risk factor for late preeclampsia alone $(\mathrm{P}<0.0001)$, while low BMI before pregnancy is found to have protective effect for both early and late preeclampsia Adjusted OR $(95 \% \mathrm{CI})(0.04(0.01-0.15))(0.39(0.26-0.61))$ respectively.

\section{Discussion:-}

In our study, we find that Early and late pre-eclampsia differs in the risk factors, Fang et al. did not find any difference in risk factors between early and late onset pre-eclampsia.(15)

The Similarities between our study and that of Fang et al. is the small sample size (443 and 150 respectively) both studies divided cases into early and late preeclampsia by subgroup analysis.(15)

The difference between this study and that of Fang et al. may be due to the difference of environmental and cultural factors in the communities of the studied groups.

In our study we find that early preeclampsia is closely associated with history of chronic hypertension and higher BMI before pregnancy, while late preeclampsia is closely associated with increased maternal age and family history hypertension or preeclampsia.

Previous history of preeclampsia, Nulliparity and family history of diabetes are associated with both early and late preeclampsia.

Duckitt K, Harrington D. studied the risk factors for preeclampsia in general, in agreement with our study they find that previous history of preeclampsia, nulliparity and pre-existing diabetes are associated with increased risk for preeclampsia, but they found that multiple (twin) pregnancy, family history, raised blood pressure (diastolic $\geq 80$ $\mathrm{mm} \mathrm{Hg}$ ) at booking, raised body mass index before pregnancy or at booking and maternal age $\geq 40$ are associated with increased risk at any gestational age.(16)

Nanjundan et al. found that history of preeclampsia or eclampsia in a previous pregnancy, exposure to passive smoking, inadequate antenatal supervision, family history of hypertension in one or more first-degree relatives, living in a joint family, being overweight and lower socioeconomic status were associated with increased risk of early onset preeclampsia and eclampsia.(17.) The difference in these studies may be due to difference in the study population.

Poon et al. agreed with our study as they found that predictors of early pre-eclampsia were African race, chronic hypertensionprior and use of ovulation drugs and Predictors of late onset pre-eclampsia and gestational hypertension were increased maternal age and family history or history of pre-eclampsia.(18) while they disagree with our study by classifying prior pre-eclampsia as risk factor for early pre-eclampsia, and higher BMI before pregnancy as risk factor for late preeclampsia.(18) The difference in these studies may be due to difference in the sample size and study population.

High BMI increased the risk of pre-eclampsia, which was explained by increase in triglyceride and free fatty acid levels with obesity. These lipid alterations can produce major factors leading to endothelial cell dysfunction in preeclampsia with increased circulating levels of lipid peroxides oxidative stress. This can lead to endothelial cell damage. $(19,20)$

SarkaLisonkova, and K.S. Joseph agreed with our study, they found that African-American race and chronic hypertension, were more strongly associated with early-onset preeclampsia and nulliparity and diabetes mellitus were more strongly associated with late-onset disease, this study disagree with our study by classifying younger maternal age as risk factor for late preeclampsia.(21) 
Another study done in Iraq by AnmarAltaeiand JumahMasoud Mohammad published at 2012 showed that there were certain risk factors significantly associated with preeclampsia incidence $\mathrm{P}<0.05$ and these were gestational age, family history, multifetal pregnancy, previous abortion, medical history including UTI and DM and social status, but this study disagreed with our study in considering maternal age as insignificant risk factors for preeclampsia.(22)

\section{References:-}

1. Kayode O. Osungbade1 and Olusimbo K. Ige. Public Health Perspectives of Preeclampsia in Developing Countries: Implication for Health System Strengthening. Journal of Pregnancy $2011: 6$.

2. Hutcheon JA, Lisonkova S, Joseph KS. Epidemiology of pre-eclampsia and the other hypertensive disorders of pregnancy. Best Pract Res ClinObstetGynaecol. 2011 Aug;25(4):391-403.

3. Cande V Ananth, Katherine M Keyes, Ronald J Wapner. Pre-eclampsia rates in the United States, 1980-2010: age-period-cohort analysis. BMJ 2013; 347 : f6564.

4. Villar J, Say L, Gulmezoglu AM, Meraldi M, Lindheimer MD, Betran AP, Piaggio G; Eclampsia and preeclampsia: a health problem for 2000 years. In Pre-eclampsia, Critchly H, MacLean A, Poston L, Walker J, eds. London, RCOG Press, 2003, pp 189-207.

5. Ronsmans C, Graham WJ on behalf of the Lancet Maternal Survival Series steering group, "Maternal mortality; who, when, where and why." The Lancet, Maternal Survival, September 2006.

6. Maternal mortality in 2005: estimates developed by WHO, UNICEF, UNIFPA and the World Bank, Geneva, World Health Organization, 2007.

7. Valensise H1, Vasapollo B, Gagliardi G, Novelli GP. Early and late preeclampsia: two different maternal hemodynamic states in the latent phase of the disease. Hypertension. 2008 Nov; 52(5): 873-80.

8. Lisonkova S1, Joseph KS. Incidence of preeclampsia: risk factors and outcomes associated with early- versus late-onset disease. Am J Obstet Gynecol. 2013 Dec ; 209(6):544.e1-544.e12.

9. Sibai BM, Caritis S, Hauth J. What we have learned about preeclampsia. SeminPerinatol. 2003;27(3):239-246.

10. 1Lindheimer MD, Taler SJ, Cunningham FG. Hypertension in pregnancy. J Am SocHypertens. 2008;2(6):484494.

11. Valensise H, Vasapollo B, Gagliardi G, Novelli GP. Early and late preeclampsia: Two different maternal hemodynamic states in the latent phase of the disease. Hypertension. 2008;52(5):873-880.

12. Judi A Turner. Diagnosis and management of pre-eclampsia: an update. Int J Womens Health. 2010; 2: 327337.

13. ACOG Committee on Obstetric Practice. ACOG practice bulletin. Diagnosis and management of preeclampsia and eclampsia. Number 33, January 2002. American College of Obstetricians and Gynecologists.Int J Gynaecol Obstet. 2002 Apr;77(1):67-75.

14. 1von Dadelszen P, Magee LA, Roberts JM.Subclassification of preeclampsia.Hypertens Pregnancy. 2003;22:143-8.

15. Fang R, Dawson A, Lohsoonthorn V, Williams MA. Risk factors of early and late onset preeclampsia among Thai women.Asian Biomed (Res Rev News) 2009; 3: 477-486.

16. Duckitt K, Harrington D. Risk factors for pre-eclampsia at antenatal booking: Systematic review of controlled studies. BMJ 2005; 330: 565-571.

17. Nanjundan P, Bagga R, Kalra JK, Thakur JS, Raveendran A. Riskfactorsforearlyonsetseverepreeclampsiaandeclampsia among north Indian women. J ObstetGynaecol 2011; 31: 384-389.

18. Poon LC, Kametas NA, Chelemen T, Leal A, Nicolaides KH. Maternal risk factors for hypertensive disorders in pregnancy: A multivariate approach. J Hum Hypertens 2010; 24: 104-110.

19. Takacs P, Kauma SW, Sholley MM, Walsh SW, Dinsmoor MJ, Green K. Increased circulating lipid peroxides in severe preeclampsia activate NF-kappaB and upregulate ICAM-1 in vascular endothelial cells. FASEB J 2001; 15: 279-281.

20. Cheng $\mathrm{MH}$, Wang PH. Placentation abnormalities in the pathophysiology of preeclampsia. Expert RevMolDiagn 2009; 9: 37-49.

21. SarkaLisonkova, and K.S. Joseph. Incidence of preeclampsia: risk factors and outcomes associated with earlyversus late-onset disease. AJOG 2013 ; 209, Issue 6: 544.e1-544.e12.

22. AnmarAltaeiand JumahMasoud Mohammad. Incidence and Risk Factors of Pre-eclampsiaAmong Iraqi Pregnant women. AJPS $2012 ; 12: 2: 52-60$. 